\title{
Recycling ceramic industry wastes in sound absorbing materials
}

\author{
C. Arenas, L.F. Vilches, C. Leiva $\bowtie$, B. Alonso-Fariñas, M. Rodríguez-Galán \\ University of Seville, Higher Technical School of Engineering, Department of Chemical and \\ Environmental Engineering (Seville, Spain) \\ $\triangle$ cleiva@us.es
}

\author{
Received 23 November 2015 \\ Accepted 24 May 2016 \\ Available on line 27 October 2016
}

\begin{abstract}
The scope of this investigation is to develop a material mainly composed $(80 \% \mathrm{w} / \mathrm{w})$ of ceramic wastes that can be applied in the manufacture of road traffic noise reducing devices. The characterization of the product has been carried out attending to its acoustic, physical and mechanical properties, by measuring the sound absorption coefficient at normal incidence, the open void ratio, density and compressive strength. Since the sound absorbing behavior of a porous material is related to the size of the pores and the thickness of the specimen tested, the influence of the particle grain size of the ceramic waste and the thickness of the samples tested on the properties of the final product has been analyzed. The results obtained have been compared to a porous concrete made of crushed granite aggregate as a reference commercial material traditionally used in similar applications. Compositions with coarse particles showed greater sound absorption properties than compositions made with finer particles, besides presenting better sound absorption behavior than the reference porous concrete. Therefore, a ceramic waste-based porous concrete can be potentially recycled in the highway noise barriers field.
\end{abstract}

KEYWORDS: Concrete; Bricks; Waste treatment; Aggregate; Particle size distribution

Citation/Citar como: Arenas, C.; Vilches, L.F.; Leiva, C.; Alonso-Fariñas, B.; Rodríguez-Galán, M. (2016) Recycling ceramic industry wastes in sound absorbing materials. Mater. Construcc. 66 [324], e106. http://dx.doi.org/10.3989/ mc.2016.10615

RESUMEN: Reciclado de residuos cerámicos en materiales absorbentes acústicos. El objetivo de este trabajo es desarrollar un material absorbente acústico compuesto fundamentalmente por residuos cerámicos $(80 \% \mathrm{p})$ que se pueda utilizar en la fabricación de dispositivos reductores de ruido de carretera. La caracterización del producto se ha llevado a cabo atendiendo a sus propiedades acústicas, físicas y mecánicas, determinando el coeficiente de absorción acústica a incidencia normal, porosidad abierta, densidad y resistencia a compresión. La absorción acústica de un material poroso está fuertemente determinada por el tamaño de poro y por la longitud dela probeta sometida a ensayo. De este modo, se ha analizado la influencia del tamaño de partícula del residuo cerámico y del espesor de las muestras estudiadas en las propiedades del producto final. Los resultados obtenidos se han comparado con los obtenidos para un hormigón poroso elaborado con árido grueso, que se ha tomado como producto de referencia tradicionalmente empleado en este tipo de aplicaciones. Las composiciones elaboradas con el residuo de mayor tamaño de partícula han mostrado mayor absorción acústica, incluso mayor que las del hormigón poroso comercial. Por tanto, un hormigón poroso elaborado con residuos cerámicos puede ser potencialmente empleado como material en la fabricación de barreras acústicas de carretera.

PALABRAS CLAVE: Hormigón; Ladrillos; Tratamiento de residuos; Árido; Distribución de tamaño de partículas

Copyright: (C) 2016 CSIC. This is an open-access article distributed under the terms of the Creative Commons Attribution License (CC BY) Spain 3.0. 


\section{INTRODUCTION}

Until the beginning of the global economic crisis in 2008, the Spanish ceramic industry accounted for $40 \%$ of European production, although in recent years the production has fallen by almost half. The generation of non-hazardous waste in this industry amount to $3 \mathrm{Kg} / \mathrm{m}^{2}$ of manufactured tile. Among all waste generated, the remains of cooked materials account for $10 \%$ of the total waste, approximately 50.000 tons a year, despite the declining of the ceramic industry production (1).

With increasing restrictions and cost on landfills in the European Union, it is necessary to find ways for reusing and recycling their wastes (2). It has been estimated that about the $40 \%$ of the daily production in the ceramic industry is landfilled. For this reason, the need for seeking new applications in other industries where the ceramic waste can be recycled is becoming absolutely vital (3). Although the reutilization of ceramic waste as fine and coarse aggregates in the concrete production has been previously studied (4-7), its use in structural concrete is not a common practice, particularly as fine aggregates (8). Thus, it seems that the best engineering applications found for recycling ceramic waste is as in non-structural concretes as recycled aggregates.

Another increasing environmental problem is the noise pollution. The source of most outdoor noise worldwide is traffic noise, including motor vehicle, plains and rail noise. Changes in the regulations have led to the creation of programs under the European Directive on the Assessment and Management of Environmental Noise (9), which are likely to lead to growth in the use of noise barriers as a way of reducing traffic noise.

Conventional noise barriers are generally designed to reflect a large proportion of traffic noise, which creates a problem when a minimization of sound reflection towards noise sensitive areas adjacent to the highway is required. Therefore, there is a need for manufacturing traffic noise barriers that can absorb noise, leading to major developments in the field of sound absorbing materials (10).

One of the most common materials used for noise barrier applications is a combination of porous concrete with a hard backing consisting of standard concrete (11). Porous concrete is made by mixing coarse aggregate material with cement, creating lots of voids in the cast concrete. As a result, the pores inside the material absorb sound energy through internal friction (12).

Many industrial waste materials, such as waste rubber, metal shavings, plastic, textile agglomerates have been demonstrated that can be used to manufacture acoustic materials. Some authors have found useful to mix various recycled materials of different grain size in order to obtain the desired performance. For this purpose, the binder proportion must be properly adjusted (13-15).

The aim of the present research has a double environmental aspect. From one side, recycling an industrial waste, and to another, reducing traffic noise pollution levels. The objective of this study is to design a product composed mainly of ceramic wastes with all different size particles, so that it can be applied in the field of road noise barriers. In order to achieve the greatest acoustic absorbing behavior of the product, the influence of the grain particle size of ceramic waste, the thickness of the panel and the combination of different layers with various particle sizes creating a composite product have been studied.

\section{MATERIALS AND METHODS}

\subsection{Materials}

The ceramic waste $(\mathrm{CW})$ presented a wide range of particle sizes, from dust to particles larger than 10 $\mathrm{mm}$. The waste material was sieved in three different sizes (coarse, medium and fine particles) as it was received from the producers without being crushed, in order to analyze the influence of the grain size in the properties of the final product. The $\mathrm{CW}$ was combined with ordinary Portland cement type II $32.5 \mathrm{~N}$ (PCII). The test specimens were manufactured following a simple, low-cost procedure. The solid components were placed in a concrete mixer and were mixed until a homogeneous mixture was achieved. Then water was added to the mixture and it was re-mixed until a workable paste was obtained. When the mixing was completed, the paste was placed in molds $(34 \mathrm{~mm}$ diameter, variable thickness) and was compacted twice using a vibrating table. The specimens were then taken out of molds after $24 \mathrm{~h}$ and left to cure at ambient conditions for 28 days.

\subsection{Test methods}

When a sound wave strikes a material, a portion of the sound energy is reflected back, another portion is absorbed by the material while the rest is transmitted. The sound absorption coefficient, $\alpha$, is the ratio of the absorbed energy to the total incident energy. To determine the acoustic properties of the products, the sound absorption coefficient at normal incidence was determined by the transfer-function method described in EN ISO 10534-2 (16) using an impedance tube connected to a sound source. An ACUPRO system has been used implemented by "Spectronics Inc.", with two microphones and a SAMSON signal amplifier. The test method consists in creating flat waves inside the tube produced by the sound source, while the microphones measure the acoustic pressure 
in two fixed positions. Afterwards, the software ACUPRO calculates the acoustic transfer complex function and then the sound absorption coefficient at normal incidence. The circumferential edge of the test sample was carefully sealed with vaseline as recommended by the ISO-10534-2, to ensure a good fit between the sample and the tube. Each value represents the average value obtained after testing three samples. The Noise Reduction Coefficient (NRC) was determined as well by calculating the arithmetic mean of the absorption coefficients at 250, 500, 1000 and $2000 \mathrm{~Hz}$, in order to have single numeric data of the sound absorption coefficient to make comparisons. Three samples for each composition have been measured. Although the NRC is widely accepted as a global absorption coefficient, the weighted sound absorption coefficient $\left(\alpha_{\mathrm{w}}\right)$ is more commonly used in the road traffic noise barrier field in Europe. This coefficient was calculated according to the standard EN 11654 (17).

The open porosity has been measured due to it is strongly related to the sound absorbing behavior of rigid frame porous structures. The method of vacuum water saturation has been followed in the determination of open void ratio (VR \%) (18). The samples were oven-dried at $105 \pm 5^{\circ} \mathrm{C}$. Subsequently, they were weighed (W1) and left under water in a vacuum vessel until saturation was reached. After 24 hours they were removed and weighed again (W2). The open void ratio was calculated by VR $(\%)=\mathrm{VW} /$ VS 100 , where VW is the volume in the sample occupied by water and VS is the total volume of the sample. The volume of water can be found as $\mathrm{VW}=(\mathrm{W} 2-\mathrm{W} 1) / \rho \mathrm{w}$, where $\rho \mathrm{w}$ is the density of water at the test temperature. Each value represents the results of measuring three samples.
The density $(\rho)$ of the mortars was calculated by weight and volume (dimensions) measurements. Four samples were measured for each value presented. The compressive strength (CS) of the test samples was determined based on the ASTM-C39/ C39M-05e2 (19) using a compression test machine (Supezcar, MEM-102/50t). Each result was obtained by testing three specimens.

\section{RESULTS AND DISCUSION}

Waste from fired red paste ceramic was used in this work. The chemical composition is showed in Table 1. As it can be seen, the silica and alumina are the most significant oxides present in the ceramic waste. The red paste shows a high proportion of iron oxide responsible of the red color of the material.

In order to analyze the influence of the particle grain size of the ceramic waste in the properties of the final product, specimens with different grain size of $\mathrm{CW}$ were manufactured. The properties of the $\mathrm{CW}$ products have been compared to a typical porous concrete (HP) (20). Table 2 shows the nomenclature, composition and water content of the samples manufactured, as well as the results of the physical and mechanical properties measured.

The water/solid ratio in the mixtures increased as the particle size is lower, due to the effect of the fineness of the particles on the workability of the mix. Lower particle size increases the surface area which makes the mixtures require more water to lubricate the particles (21). On the other hand, the open porosity of the mortars tended to rise when the particle size is larger. The particle size distribution of HP is wider than the particle distribution of $\mathrm{CW}-\mathrm{C}$, but its medium particle size is lower than

TABLE 1. Chemical composition of ceramic wastes

\begin{tabular}{lcccccccc}
\hline $\mathbf{S i O}_{2}$ & $\mathbf{A l}_{2} \mathbf{O}_{3}$ & $\mathbf{F e}_{2} \mathbf{O}_{3}$ & $\mathbf{C a O}$ & $\mathbf{M g O}$ & $\mathbf{N a}_{2} \mathbf{O}$ & $\mathbf{K}_{2} \mathbf{O}$ & $\mathbf{T i O}_{2}$ & $\mathbf{L O I}$ \\
\hline 57.7 & 19.7 & 6.3 & 6.4 & 2.6 & 0.3 & 4.7 & 0.7 & 1.6 \\
\hline
\end{tabular}

TABle 2. Composition ( $\mathrm{wt} \%$ ) and properties of $\mathrm{CW}$ specimens and porous concrete

\begin{tabular}{lcccc}
\hline & CW-Coarse & CW-Medium & CW-Fine & HP \\
\hline CW (\%) & 80 & 80 & 80 & - \\
PCII (\%) & 20 & 20 & 20 & 20 \\
Coarse aggregate (\%) & - & - & - & 80 \\
Particle size (mm) & $2.5<\mathrm{d}_{\mathrm{p}}<4.5$ & $1.25<\mathrm{d}_{\mathrm{p}}<2.5$ & $\mathrm{~d}_{\mathrm{p}}<1.25$ & $3<\mathrm{d}_{\mathrm{p}}<9$ \\
Medium particle size (mm) & 3.9 & 2.1 & 0.9 & 3.4 \\
\% size over original CW & 57 & 28 & 15 & - \\
Water/solid (\%) & 25 & 28 & 35 & 9 \\
Open porosity (\%) & 30 & 18 & 9 & 23 \\
Density $\left(\mathrm{kg} / \mathrm{m}^{3}\right)$ & 1180 & 1230 & 1500 & 1730 \\
Compressive strength $(\mathrm{MPa})$ & 2.9 & 3.5 & 4.3 & 3.4
\end{tabular}


the medium particle size of $\mathrm{CW}-\mathrm{C}$. In consequence, $\mathrm{CW}-\mathrm{C}$ was the product with highest open porosity, followed by HP, CW-M and CW-F, which presented very low open porosity. Figure 1 shows the appearance of the samples after 28 days of curing, and it can be observed the different open porosity of the samples.

The density of the products increased as the particle size becomes finer. Although CW-F showed the lowest porosity, it presented the greatest density of the $\mathrm{CW}$ products. Although the porous concrete used as a reference had an open void ratio close to $\mathrm{CW}-\mathrm{C}$, it presented higher density than CW-C composition. This fact is due to the greater specific gravity of the coarse aggregate $\left(2.69 \mathrm{~g} / \mathrm{cm}^{3}\right)$ than the specific gravity of the ceramic waste $\left(2.15 \mathrm{~g} / \mathrm{cm}^{3}\right)$. The mechanical properties of the $\mathrm{CW}$ products showed that the compressive strength of the mortars decreased when the open void ratio increases. Therefore, the most porous materials had the weakest compressive strength.

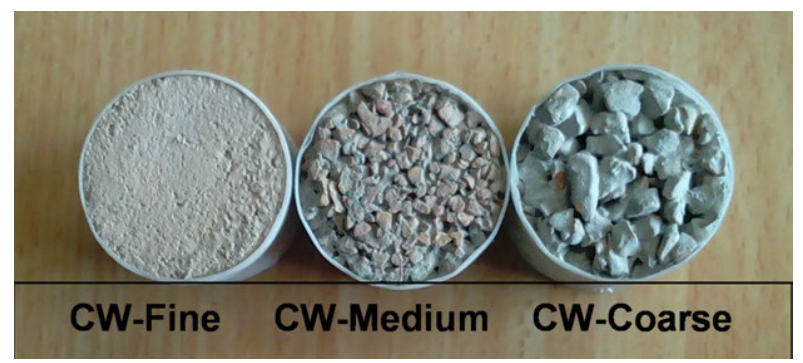

FIGURE 1. Samples of the different compositions.
The variation of the acoustic absorption coefficient in the different $\mathrm{CW}$ products and porous concrete is shown in Figure 2. The results of the sound absorption coefficient are represented in one-third octave bands. The sound absorption of a porous material is related to the energy loss by friction produced in the walls of its holes. As a result, CW mortars with higher open porosity presented better sound absorption coefficients in the whole range of frequencies. Compared to the porous concrete, HP had similar sound absorption coefficients to $\mathrm{CW}-\mathrm{C}$, as it happened when comparing the open porosity. The maximum peak of the sound absorption coefficient registered for $\mathrm{CW}-\mathrm{C}$ appeared at $800 \mathrm{~Hz}$, which is positive taking into account that noise levels at frequencies lower than $1000 \mathrm{~Hz}$ are the most difficult to reduce.

On the other hand, the acoustic absorption of a porous material depends on the thickness of the specimen tested. For this purpose, tests on the same compositions of $\mathrm{CW}$ products with different thicknesses were carried out. Figure 3 shows the sound absorption coefficient curves for 40 (L1), 80 (L2) and $120 \mathrm{~mm}$ (L3) thicknesses of CW-C specimens. The acoustic absorption spectra of CW-C specimens shifted towards lower frequency levels as the thickness of the specimens becomes larger, although the magnitude of the absorption coefficient peak remained practically uniform. This phenomenon could be due to the relationship between the peak frequency and the thickness of the specimens (equation a), which can be expressed by an equation [1] obtained from the concept of the absorbing mechanism of a porous material (22).

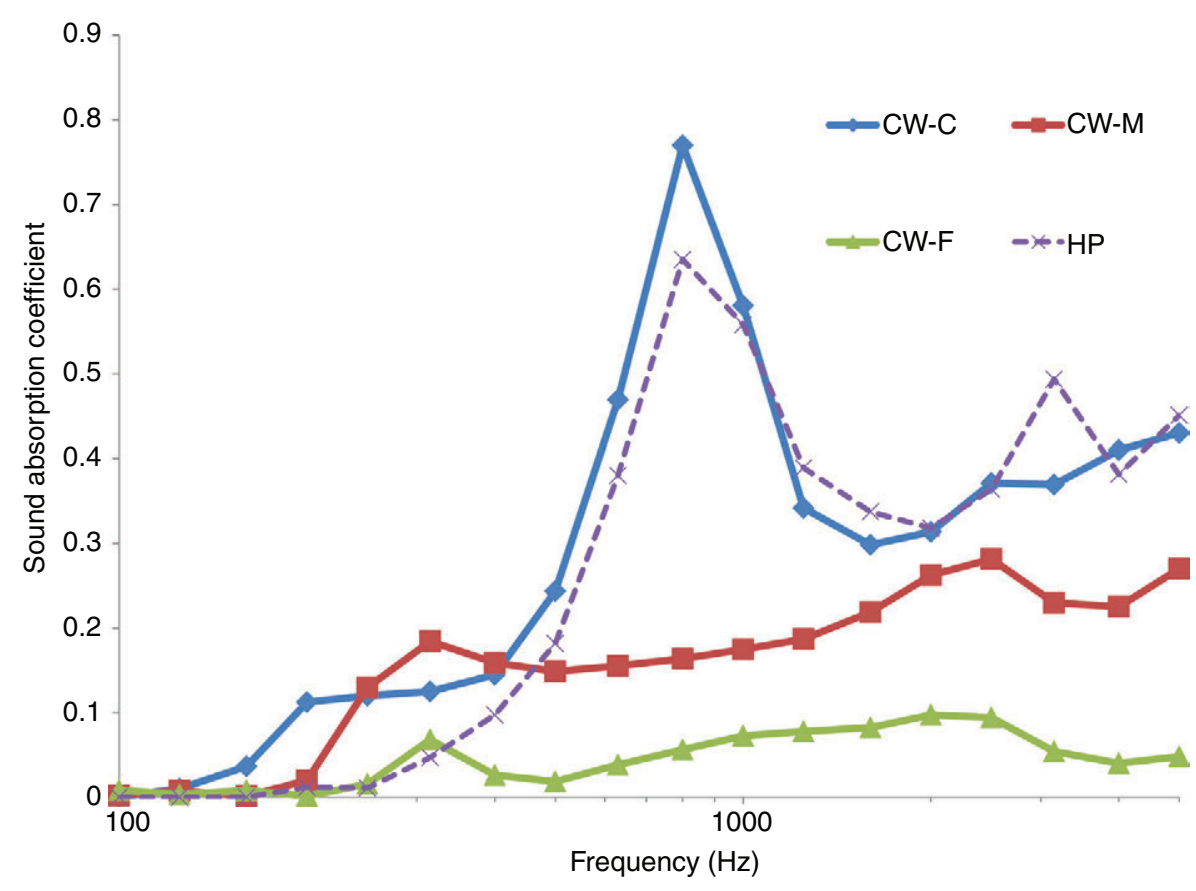

FIGURE 2. Normal incidence sound absorption coefficient. 


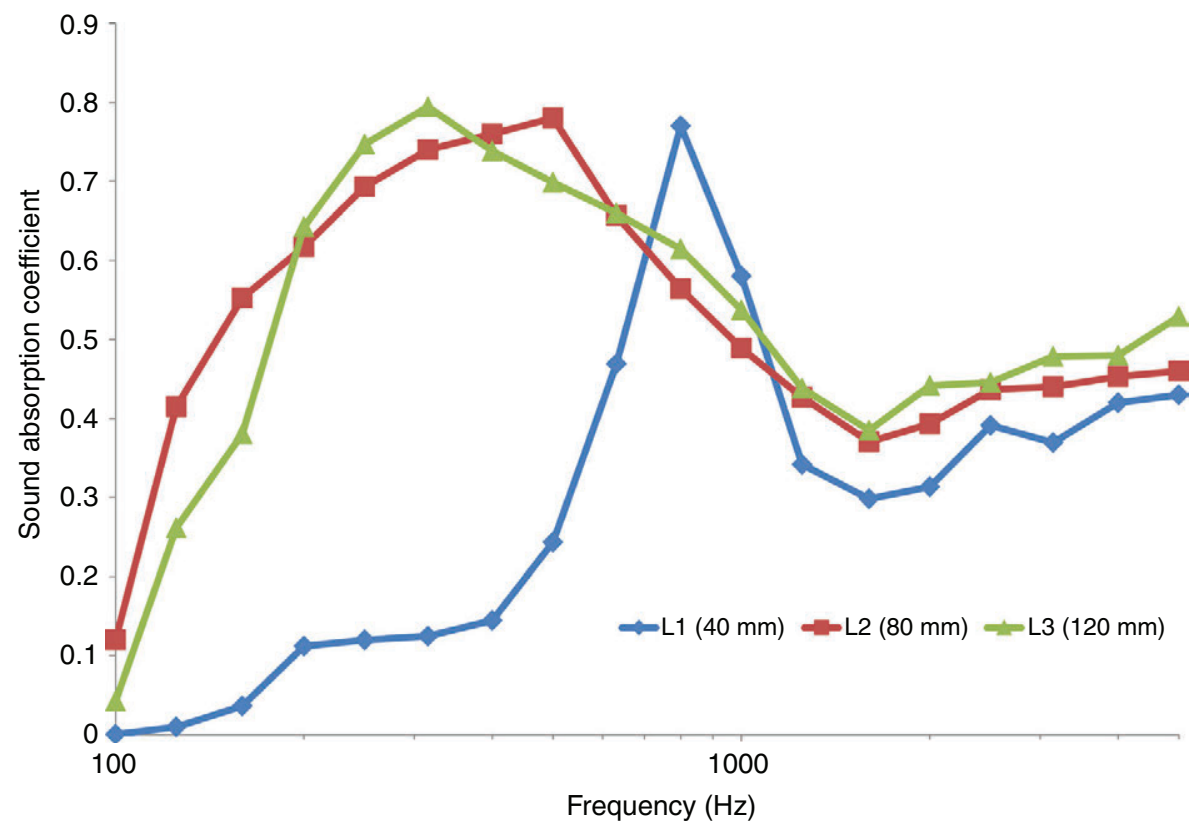

FIGURE 3. Influence of the thickness of CW-C on the sound absorption coefficient.

TABLE 3. NRC and $\alpha_{w}$ of CW-C, CW-M, CW-F with different thickness

\begin{tabular}{|c|c|c|c|c|c|c|c|c|}
\hline & \multicolumn{2}{|c|}{$\mathrm{CW}-\mathrm{C}$} & \multicolumn{2}{|c|}{ CW-M } & \multicolumn{2}{|c|}{ CW-F } & \multicolumn{2}{|c|}{ HP } \\
\hline & NRC & $\alpha_{w}$ & NRC & $\alpha_{w}$ & NRC & $\alpha_{w}$ & NRC & $\alpha_{w}$ \\
\hline $\mathrm{L} 1-40 \mathrm{~mm}$ & 0.31 & 0.30 & 0.18 & 0.20 & 0.05 & 0.10 & 0.27 & 0.25 \\
\hline $\mathrm{L} 2-80 \mathrm{~mm}$ & 0.59 & $0.55(\mathrm{M})$ & 0.27 & 0.30 & 0.06 & 0.10 & - & - \\
\hline $\mathrm{L} 3-120 \mathrm{~mm}$ & 0.61 & $0.60(\mathrm{M})$ & 0.32 & 0.35 & 0.08 & 0.10 & - & - \\
\hline
\end{tabular}

$$
\mathrm{fp} \cdot 1=\frac{(2 \mathrm{n}-1) \cdot c}{4}=\mathrm{constant}
$$

Where $f_{P}$ is the frequency at the peak, $n$ is the number of peaks (constant), $c$ is the sound speed of air (fixed for temperature), and $l$ is the thickness of the specimen. Therefore, when a reduction of noise at a specific frequency is required, the thickness of the panel is an important design parameter that must be properly adjust. The same tendency was observed in the results of CW-M and CW-F, although in the case of CW-F the sound absorption was so low that very little differences were found with the variation of the thickness.

The Noise Reduction Coefficient (NRC) and $\alpha_{\mathrm{w}}$ were calculated in order to clearly identify the effect of the particle grain size of the ceramic waste material and the thickness of the specimens tested in the Kundt tube, see Table 3. The same tendency as the sound absorption coefficient curves was observed for the NRC and $\alpha_{w}$, and this effect was repeated in all the $\mathrm{CW}$ compositions. The European normative EN-ISO 11654 (17) allows the products to be classified according to the $\alpha_{w}$. CW-C-L3 can be classified as class $\mathrm{C}\left(0.6<\alpha_{\mathrm{w}}<0.75\right), \mathrm{CW}-\mathrm{F}$ is out of classification whilst the rest of the compositions are class $\mathrm{D}$ $\left(0.30<\alpha_{w}<0.55\right)$ or $\mathrm{E}\left(0.15<\alpha_{\mathrm{w}}<0.25\right)$. According to the normative, CW-C-L3 and CW-C-L2 present a favorable deviation higher than 0.25 for $500 \mathrm{~Hz}$ and should be classified as M.

Our goal is to develop a product elaborated with the entire range of $\mathrm{CW}$ particle sizes, although not all of them have the same influence on the properties of the final product as it has been demonstrated so far. The next stage of this research consisted in manufacturing a multilayer composite product using two or three layers made of different particle size fractions.

Accordingly, $12 \mathrm{~cm}$-thick specimens were prepared combining layers of CW-Coarse, Medium and Fine. Taking into account the results obtained in previous studies (20), the optimal composite solution (OCS) will be the combination which presents the best acoustic absorption behavior using all the range of particle size. The OCS is given by having $\mathrm{CW}-\mathrm{C}$ in the incident noise face $(4 \mathrm{~cm})$, followed by $\mathrm{CW}-\mathrm{M}(4 \mathrm{~cm})$ and finally $\mathrm{CW}-\mathrm{F}(4 \mathrm{~cm})$. Figure 4 presents the sound absorption coefficient curves of the OCS and CW-C. Wider layers of CW-C give 


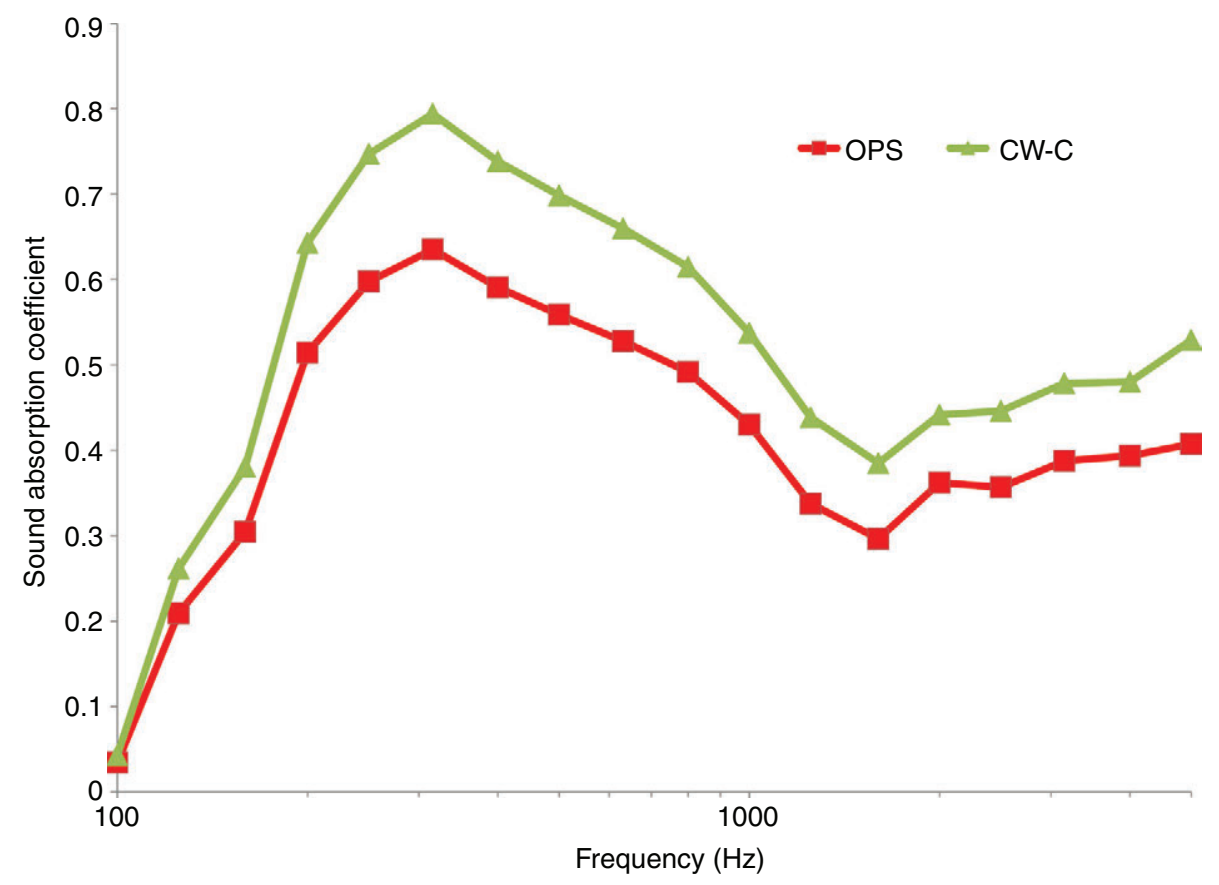

FIGURE 4. Acoustic absorption coefficient of $\mathrm{CW}$ composite products.

better sound absorption coefficient values. The less porous material as a back layer of the product increases the reflection of the sound wave, making the noise cross again the high absorption zone and increasing the total absorbed noise while keeping the thickness.

The OCS presents lower noise reduction coefficient than CW-C. Despite the fact that the NRC of the OCS is $0.49,20 \%$ less than $\mathrm{CW}-\mathrm{C}$, this composition uses all the different sizes of the ceramic waste material.

\section{CONCLUSIONS}

The recycled porous concrete present better acoustic and mechanical properties than the porous concrete traditionally used to manufacture highway noise barriers. Furthermore, the fabrication process and its potential installation are similar to the porous concrete as well. Therefore, the recycled ceramic concrete could be applied to manufacture road traffic noise reducing devices. The main goal of this experimental study was to develop a product mainly composed by ceramic waste, which presents good noise absorption characteristics. In the course of the study the following conclusions were reached:

- The grain particle size of CW influenced the acoustic behavior and the physical and mechanical properties of the products made of $\mathrm{CW}$. The best sound absorption coefficients were measured in products with the largest CW particle sizes, which developed a more porous matrix.
On the other hand, good mechanical properties have been found in the products made of the finest particles.

- The acoustic absorption coefficient spectra depends on the thickness of the specimen tested. The principal maximum of the absorption coefficient displaced to lower frequencies when the thickness increased.

- All CW particle size fractions could be recycled in this kind of application. The optimal multilayer composite product is composed of a layer containing the largest $\mathrm{CW}$ particles in the incident noise face of the product, followed by the material made using the medium CW particle size and finally, the finest CW particle size material. The composite product presents a slightly lower sound absorption behavior than CW-C with the same thickness, but it allows recycling the whole ceramic waste material.

\section{REFERENCES}

1. Criado, E.; Sánchez, E.; Regueiro, M. (2004) All tiled up: Spanish ceramics and glass. Ind. Miner. 444, 48-55.

2. Fernandes, M.; Sousa, A.; Dias, A. (2004) Environmental impact and emissions trade. Ceramic industry. A case study. Portuguese Association of Ceramic Industry APICER (2004).

3. Pacheco-Torgal, F.; Jalalib, S. (2010) Reusing ceramic wastes in concrete. Construct. Build. Mater. 24 [5], 832-838. http://dx.doi.org/10.1016/j.conbuildmat.2009.10.023

4. Senthamarai, R.M.; Devadas Manhoharan, P. (2005) Concrete with ceramic waste aggregate. Cem Concr Comp, 27 [9-10], 910-913. http://dx.doi.org/10.1016/j. cemconcomp.2005.04.003 
5. Martins, D.J.; Correia, J.R.; De Brito, J. (2016) The effect of high temperature on the residual mechanical performance of concrete made with recycled ceramic coarse aggregates. Fire Mater, 40 [2], 289-304. http://dx.doi.org/10.1002/fam.2287

6. Medina, C.; Juan, A.; Frías, M.; Sánchez de Rojas, M.I.; Morán, J.M.; Guerra, M.I. (2011) Characterization of Concrete made with Recycled Aggregate from Ceramic Sanitary Ware. Mater. Construc, 61 [304], 533-546. http:// dx.doi.org/10.3989/mc.2011.59710

7. Zhao, X.; Tung-Chai, L.; Chi-Sun, P.; Shi-Cong, K.; Qingyuan, W.; Runqiu, H. (2013) Properties of partition wall blocks prepared with high percentages of recycled clay brick after exposure to elevated temperatures. Constr. Build. Mater, 49, 56-61. http://dx.doi.org/10.1016/j. conbuildmat.2013.08.004

8. De Brito, J.; Pereira, A.S.; Correia, J.R. (2005) Mechanical behavior of non-structural concrete made with recycled ceramic aggregates. Cem. Concr. Comp., 27 [4]. 429-433. http://dx.doi.org/10.1016/j.cemconcomp.2004.07.005

9. European Parliament Directive relating to the assessment and management of environmental noise 2002/49/EC, European Parliament and of the Council (2002).

10. Crombie, H.; Hothersal, D.C. (1994) The performance of multiple nois barriers. J Sound Vib, 176 [4], 459-473. http:// dx.doi.org/10.1006/jsvi.1994.1389

11. Kim, K.; Lee, H.K. (2010) Acoustic absorption modeling of porous concrete considering the gradation and shape of aggregates and void ratio. J Sound Vib, 329 [7], 866-879. http://dx.doi.org/10.1016/j.jsv.2009.10.013

12. Nelson, P.M.; Phillips, S.M. (1994) Designing porous road surfaces to reduce traffic noise. TRL Annual Review, Transportation Research Laboratories, UK (1994).
13. Asdrubali, F.; Schiavoni, S.; Horoshenkov, K.V. (2012) A Review of Sustainable Materials for Acoustic Applications. J. Build. Acoust., 19 [4], 283-312. http://dx.doi. org/10.1260/1351-010X.19.4.283

14. R. Del Rey, R.; Alba, J.; Blanes, M.; Marco, B. (2013) The acoustic absorption of textile curtains on the function of the fullness. Mater. Construc, 63 [312], 569-580. http:// dx.doi.org/10.3989/mc.2013.05512

15. Ramis, J.; del Rey, R.; Alba, J.; Godinho, L.; Carbajo, L. (2014) A model for acoustic absorbent materials derived from coconut fiber. Mater. Construcc. 64 [313], e008. http:// dx.doi.org/10.3989/mc.2014.00513

16. EN-ISO-10534-2:1998. Acoustics determination of sound absorption coefficient and impedance or admittance by the impedance tube. Part II: Transfer function method.

17. EN-ISO 11654: 1998. Acoustic. Sound absorbers for use in buildings. Rating of sound absorption.

18. EN-1936:2006. Determination of real density and apparent density, and of total and open porosity.

19. ASTM-C39/C39M-05e2:2005. Standard test method for compressive strength of cylindrical concrete specimens, ASTM International.

20. Arenas, C.; Leiva, C.; Vilches, L.F.; Cifuentes, H. (2013) Use of co-combustion bottom ash to design an acoustic absorbing material for highway noise barriers. Waste Manage, 33, 2316-2321. http://dx.doi.org/10.1016/j. wasman.2013.07.008

21. Neville, A.Q.M. (1995) Properties of Concrete, fourth ed. Pearson Education Limited, London, (1995).

22. Neithalath, N. (2004) Development and characterization of acoustically efficient cementations materials. Purdue University (2004). 